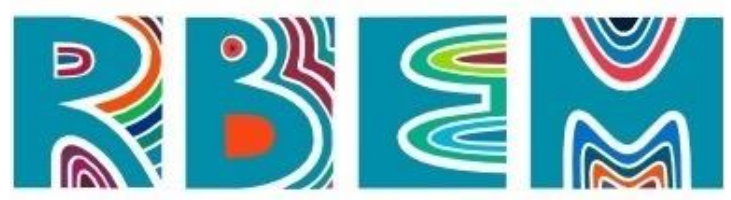

REVISTA BAIANA DE EDUCAÇÃO MATEMÁtICA

ARTIGO

http://dx.doi.org/10.47207/rbem.v1i0.9095

\title{
Aprendizagem Matemática por meio da Componente Curricular Desenho Geométrico: algumas considerações tangíveis
}

\author{
CONCEIÇÃO, Jefferson Correia da \\ Universidade do Estado da Bahia (Uneb). Doutor em Ciências da Educação pela Universidade Tecnológica \\ Intercontinental (UTIC). Professor Titular do Departamento de Ciências Exatas e da Terra da Universidade do \\ Estado da Bahia, Campus II. ORCID: https://orcid.org/0000-0002-8898-1303. E-mail: \\ jeffersoncorreia2@gmail.com.
}

Resumo: Este artigo apresenta algumas reflexões acerca de estudos envolvendo os componentes curriculares Desenho Geométrico e Matemática a partir das atividades docentes num contexto acadêmico em sala de aula com licenciandos em Matemática. A pesquisa configura-se como bibliográfica e de campo. Os dados foram analisados por meio da leitura de bibliografias específicas, observações e dos depoimentos dos licenciandos. Os resultados iniciais apresentaram percepções relevantes para efetivação dos estudos, apesar dos licenciandos pesquisados terem evidenciado inicialmente interlocuções limitadas entre as componentes curriculares citadas. Concluiu-se que, mediante os estudos a respeito da aprendizagem Matemática por intermédio do Desenho Geométrico, que é possível dinamizar, motivar e envolver muito mais os licenciandos, entendendo-se tais articulações entre as componentes mencionadas como motivação, ponto de partida, suporte e estímulos para os licenciandos, sobretudo, no que tange ao conhecimento matemático, com uma tessitura mais dinâmica, ativa e prazerosa, mesmo com a necessidade de ajustes e melhorias ao longo do processo, que se entende, como natural.

Palavras-chave: Matemática. Desenho Geométrico. Aprendizagens. Mediações.

\section{Mathematics Learning Through the Curricular Component Geometric Design: some tangible considerations}

\begin{abstract}
This article presents some reflections about studies involving the curriculum components Geometric Design and Mathematics from teaching activities in an academic context in the classroom with undergraduate Mathematics students. The research is configured as bibliographic and field. The data were analyzed through the reading of specific bibliographies, observations and testimonies of the graduates. The initial results showed relevant perceptions for carrying out the studies, despite the researched undergraduate students initially showing limited interlocutions between the curriculum components mentioned. It was concluded that, through the studies on Mathematical learning through Geometric Design, it is possible to dynamize, motivate and involve the graduates much more, understanding such articulations between the mentioned components as motivation, starting point, support and incentives for undergraduates, especially with regard to mathematical knowledge, with a more dynamic, active and pleasurable texture, even with the need for adjustments and improvements throughout the process, which is understood as natural.
\end{abstract}

Keywords: Mathematics. Geometric Design. Learning. Mediations. 


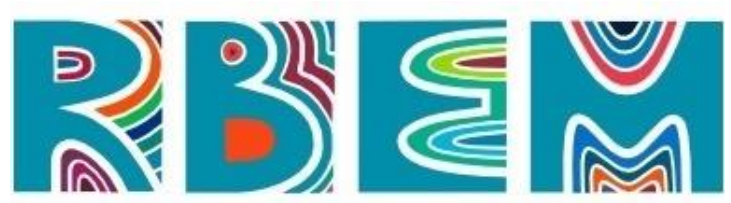

REVISTA BAIANA DE EDUCAÇÃO MATEMÁTICA

\title{
Aprendizaje de las Matemáticas a través del Diseño Geométrico de Componentes Curriculares: algunas consideraciones tangibles
}

\begin{abstract}
Resumen: Este artículo presenta algunas reflexiones sobre los estudios que involucran los componentes curriculares Diseño geométrico y Matemáticas de las actividades de enseñanza en un contexto académico en el aula con graduados en Matemáticas. La investigación se configura como bibliográfica y de campo. Los datos fueron analizados mediante la lectura de bibliografías específicas, observaciones y los testimonios de los estudiantes de pregrado. Los resultados iniciales mostraron percepciones relevantes para llevar a cabo los estudios, aunque los estudiantes universitarios encuestados inicialmente mostraron interlocuciones limitadas entre los componentes del plan de estudios mencionados. Se concluyó que, a través de los estudios sobre aprendizaje matemático a través del diseño geométrico, es posible dinamizar, motivar e involucrar a los graduados mucho más, entendiendo tales articulaciones entre los componentes mencionados como motivación, punto de partida, apoyo y incentivos para estudiantes universitarios, especialmente con respecto al conocimiento matemático, con una textura más dinámica, activa y placentera, incluso con la necesidad de ajustes y mejoras a lo largo del proceso, lo que se entiende como natural.
\end{abstract}

Palabras clave: Matemáticas. Diseño geométrico. Aprendizaje. Mediaciones.

\section{Introdução}

De maneira geral, sabe-se que, um dos objetivos do Desenho Geométrico enquanto área de estudos reside na obtenção de formas visuais determinadas, geométricas e exatas, estruturadas graficamente, objetivas e diretas, consoantes com valores, medidas, dimensões e cálculos. As realizações geométricas necessitam ser apresentadas e realizadas conforme os respectivos conceitos e definições, sempre desenvolvidas mediante processos geométricos específicos e sequenciais.

Dessa forma, raciocínio lógico e criatividade podem ser responsáveis por realizações estimulantes do ponto de vista matemático, gráfico e geométrico, uma vez que, tais habilidades, são responsáveis por grandes avanços do homem ao longo da história. Dai podese afirmar que, da lâmpada elétrica aos atuais smartphones, passando pelo avião e pelo relógio de pulso, significativas inovações são e foram alcançadas com base nessa combinação de habilidades - raciocínio lógico e criatividade, por conseguinte, mediante um desenho, um projeto gráfico ou esboço.

No entanto, desenvolver essas diferentes formas de funcionamento da mente representa um desafio para alguns educadores, sobretudo quando se tenta articular o Desenho Geométrico com componentes curriculares aparentemente distintos, como a Matemática, que 


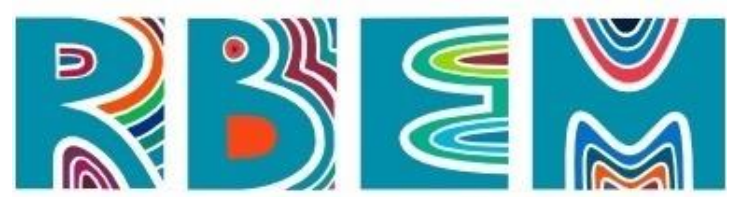

REVISTA BAIANA DE EDUCAÇÃO MATEMÁTICA

numa abordagem inicial e muito superficial, não se percebem algumas conexões importantes para se estabelecer a mediação pedagógica entre as componentes citadas, pois ambas, em larga escala de compreensão, se apoiam em medidas, adoção de regras, valores propriamente entendidos.

Curiosamente, os acadêmicos são naturalmente criativos e inovadores, características que se enfraquecem à medida que "aprendem" com alguns docentes a forma "correta" de agir e pensar. Quando, por exemplo, um estudante realiza um desenho numa perspectiva não convencional, dita "correta", logo aparece um adulto ou docente mediador para "ensinar" que as linhas estão erradas, tortas ou inadequadas. Naturalmente, aqui nos referimos ao desenho livre, artístico, que difere totalmente do Desenho Geométrico que se apoia em regras, medidas, valores geométricos propriamente entendidos.

O que leva a essa recomendação ou observação por parte de alguns docentes? Existe prejuízo em deixar um estudante desenhar inicialmente de forma livre? De maneira geral, ser criativo tem mais a ver com "desaprender" antigas formas de pensar e agir do que com adquirir habilidades especiais e diferenciadas. E a formação do docente "mediador", de quem se propõe a levar adiante tal comportamento? Qual é de fato a formação de quem desempenha esse papel pedagógico?

É preciso compreender, que é necessário que os estudantes consigam responder "para que" estão aprendendo tal conteúdo, assim como, os docentes mediadores possam responder "para que" estão mediando, a fim de que estabeleçam vínculos entre universidade e vida e, além disso, vejam relações entre conteúdos das diversas componentes curriculares, uma vez que, como se sabe, o conhecimento proporcionado pelo Desenho Geométrico não é estanque e que com isso, possam aprender, percebendo os nexos e sentidos, coerências, fundamentos e necessidades prévias para sua compreensão, podendo facilitar, em alguns casos, a compreensão geométrico - matemática.

É preciso saber com clareza, para mediar com eficiência, quais as contribuições de cada um dos conteúdos do Desenho Geométrico para os processos de desenvolvimento e aprendizagem dos acadêmicos em matemática.

Dessa forma, as atividades realizadas em sala de aula, devem explicitar conceitos, definições e fundamentos que possam facilitar a aprendizagem matemática sempre num viés 


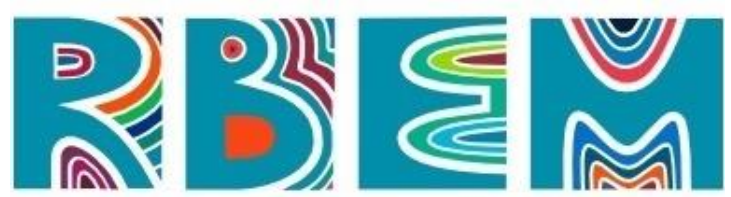

REVISTA BAIANA DE EDUCAÇÃO MATEMÁTICA

que considere o Desenho Geométrico como componente que traduz graficamente algumas compreensões matemáticas e geométricas.

Sendo assim, o objetivo principal desse artigo é perceber e registrar as contribuições do estudo da componente curricular Desenho Geométrico para aprendizagem matemática, no curso de licenciatura em Matemática, do Campus II - Uneb, por intermédio da participação dos estudantes ingressantes que são contemplados com a oferta da componente ao chegarem a Universidade e com estudantes concluintes, uma vez que, realizaram estudos com demais componentes que compõem o currículo do curso mencionado e poderão enfatizar as articulações e aprendizagens ocorridas que tiveram o aporte do Desenho Geométrico para aprendizagem matemática.

Diante dessa perspectiva, refletiu-se sobre as possibilidades e caminhos a serem percorridos para obtenção de respostas, quando foi possível optar pela pesquisa-ação, por possibilitar responder ao pesquisador e aos participantes diretamente envolvidos, conforme questões postas pela pesquisa e pelas situações vivenciadas pelos acadêmicos, sob a forma de uma ação transformadora, querendo buscar soluções para questões apontadas (GIL, 2008).

Utilizou-se também, algumas rodas de conversas, reuniões e outras atividades, dentro de um processo de construção participativo e colaborativo, pois se entendeu que, ações dessa natureza, seriam de extrema importância e necessidade para que se desse inicio ao processo de trabalho, criando-se assim, condições mais adequadas para coletar os dados conforme objetivo proposto, mediante adoção de metodologia de pesquisa com abordagem qualitativa e de caráter exploratório, conforme procedimentos mencionados.

Para melhor compreensão do estudo, o artigo está organizado em quatro tópicos. Primeiro, apresentam-se algumas tessituras acerca da temática que origina o trabalho com uma breve introdução. Em seguida, o desenvolvimento do artigo propriamente dito, quando se apresenta os percursos metodológicos, características do público envolvido e uma breve descrição a respeito do ambiente de trabalho. Apresentam-se também, apontamentos importantes sobre Desenho Geométrico e Matemática, no que tange as finalidades, concepções, objetivos etc. A terceira seção destaca as evidências de aprendizagem ao se entrelaçar a Matemática e o Desenho Geométrico enquanto possibilidades pedagógicas, conforme depoimentos dos acadêmicos participantes da pesquisa. O quarto tópico traz as considerações transitórias, com as principais questões e percepções coletadas. 


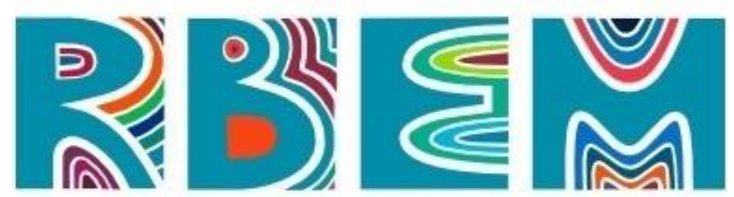

REVISTA BAIANA DE EDUCAÇÃO MATEMÁTICA

\section{Desenvolvimento}

Considerando-se os questionamentos e percepções anteriores, é que se pensa na possibilidade de articulação do Desenho Geométrico enquanto campo de conhecimentos, componente curricular e/ou área de estudos, com todos os seus desdobramentos expressivos, como aliada pedagógica numa prática que se quer dinâmica, viva e prazerosa que facilite a aprendizagem matemática.

Em outras palavras, as possibilidades expressivas, práticas e teóricas do Desenho Geométrico, quando adotado de forma articulada na práxis docente, objetivando a aprendizagem matemática, entre outras, poderão trazer mais conhecimentos e serem mais eficazes como portador de informação e sentido, sendo um convite ao exercício prático de aprender a ver, observar, ouvir, tocar, atuar, analisar, perceber e refletir geometricamente.

Desse modo, os acadêmicos poderão perceber melhor as informações que lhes são apresentadas, poderão ampliar infinitamente capacidades expressivas e de comunicação matemática. No que diz respeito às teorias enquanto alimento para prática pedagógica, vejamos o que é dito por D’Ambrósio (2006, p. 79).

[...] Entre teoria e prática persiste uma relação dialética que leva o indivíduo a partir para a prática equipado da teoria e a praticar de acordo com essa teoria até atingir os resultados desejados. Toda teorização se dá em condições ideais e somente na prática serão notados e colocados em evidencia certos pressupostos que não podem ser identificados apenas teoricamente. Isto é, partir para a prática é um mergulho no desconhecido.

Pelo exposto, verifica-se que ações com perfis integradores - teoria e prática poderão contemplar os objetivos integracionistas do Desenho Geométrico e a Matemática, uma vez que, devem ser compreendidas em função da curiosidade, interesse e envolvimento que são manifestados pelos acadêmicos no decorrer das ações empreendidas, além, evidentemente, dos resultados práticos evidenciados, sem prejuízo da qualidade gráfica pretendida. Isso poderá permitir propiciar a tomada de consciência da existência de uma produção genuína, real e concreta, em permanente elaboração acerca do conhecimento proporcionado pelo Desenho Geométrico articulado com a Matemática. 


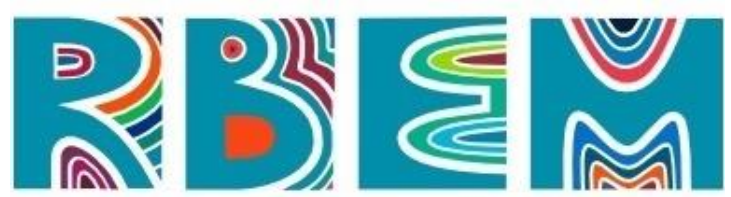

REVISTA BAIANA DE EDUCAÇÃO MATEMÁTICA

Segundo Cifuentes (2005), os futuros professores de matemática são convidados a compreender que não estão sozinhos na mediação pedagógica, mas nas relações estabelecidas nos espaços educativos, na interação entre diferentes componentes curriculares e conduzidas infinitamente pelas questões sociais. Este pensamento dialoga com as colocações de D’ambrósio (2006) e Silva (2006), ao proporem que a responsabilidade docente pela mediação do conhecimento matemático fica a cargo da sua condição de perceber possibilidades articulativas, baseada em seus conhecimentos, representações e intencionalidades no que se refere à Matemática enquanto campo de conhecimentos e área de estudos, dotada de inúmeras tessituras curriculares.

Nesse sentido, Helbel (2013) defende que a educação matemática não é uma prática a ser desenvolvida apenas num viés com as ditas ciências exatas, mas precisa ser trabalhada de forma conjugada com todas as áreas do conhecimento interdisciplinar, como consta nos documentos oficiais e literaturas estabelecidas que normatizam o assunto.

Assim, considerando também como referência os estudos realizados por Zuin (2001) verifica-se que, a formação de professores de modo geral, não deve abdicar das experiências pessoais, saberes, histórias e, especialmente, os seus percursos formativos com suas pluralidades, dimensões, fronteiras, métodos e estratégias que permearam ou não todo o processo formativo no qual esses professores estiveram imersos, pois segundo o autor, essa dimensão será crucial para o amadurecimento profissional dos futuros docentes.

Desse modo, para Costa (2013) participação e tomada de decisões consiste no aumento de possibilidades para eficiência de uma formação acadêmica mais sólida em matemática, norteadora de atividades educativas plurais, articulativas, ricas e eficientes, uma vez que, em ações dessa natureza, podem-se estimular os licenciandos a se comportarem como futuros pesquisadores, mediante uma postura de aprendizagem profissional permanente, objetivando suas futuras ações em sala de aula.

\section{Percursos metodológicos, perfil público envolvido e características do ambiente de trabalho}

Para efetivação das atividades pedagógicas em sala de aula, organiza-se a apresentação inicial das ações para os acadêmicos do primeiro semestre, esclarecem-se os assuntos e 


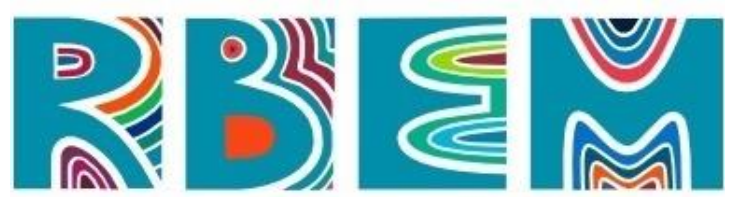

REVISTA BAIANA DE EDUCAÇÃO MATEMÁTICA

conteúdos para o encontro, por meio de exposições dialogadas sobre os objetivos e propósitos para o ciclo de atividades no semestre.

Os participantes são licenciandos do primeiro semestre do Curso de Matemática, regularmente matriculados na Universidade do Estado da Bahia - UNEB - Campus II, na cidade de Alagoinhas - BA. Estão numa faixa etária dos 17 aos 23 anos, conforme pesquisa realizada na Secretaria Acadêmica do Campus.

As atividades ocorrem durante os semestres acadêmicos, por meio de 03 (três) aulas semanais, com carga horária total de 45 horas, em 15 (quinze) semanas letivas. A sala de aula para Desenho não é equipada com pranchetas, possui apenas mesas convencionais do tipo escolar, que propiciam razoavelmente algum conforto para os acadêmicos para realização das atividades. Contudo, bem ampla, climatizada, bem iluminada, arejada. Possui também, dois armários de chapas metálicas, para guardar materiais, atividades dos estudantes, etc.

As turmas iniciais são compostas por 40 (quarenta) acadêmicos, que formam duas turmas T.01 e T.02, tendo em cada uma 20 (vinte) estudantes, com o propósito de estreitar o contato, facilitar a assimilação e fornecer atenção mais direta aos recém-chegados na Universidade, na primeira fase. Nessas turmas, por vezes, são incluídos alguns acadêmicos que aproveitam a ocasião para cursarem e integrarem o semestre, por vários motivos -

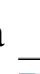
desistências semestres anteriores, repetições etc.

Foram 28 (vinte e oito) acadêmicos do sexo feminino e 12 (doze) do sexo masculino para realização da pesquisa. São oriundos das áreas urbana e rural, dentre outros municípios da microrregião de Alagoinhas, bem como, de outras microrregiões. O espaço temporal para realização da pesquisa ocorreu a partir do primeiro semestre 2018 ao segundo semestre do ano de 2019.

Costumeiramente, nos contatos iniciais, os acadêmicos da primeira fase são orientados para perceberem as imagens do ambiente imediato da sala de aula, ou seja, as formas visuais em geral, de modo livre, do local onde se encontram. Posteriormente, sugere-se também, que observem as imagens bidimensionais e tridimensionais nas suas respectivas residências, locais de trabalho, na cidade, nos percursos na cidade até a chegada à instituição de estudo, para que possam desenvolver cada vez mais a observação, a atenção e o conhecimento geométrico que já possuem para agregar aos propósitos dos trabalhos sugeridos. 


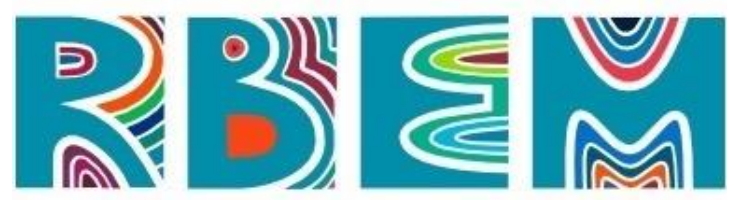

REVISTA BAIANA DE EDUCAÇÃO MATEMÁTICA

Durante a dinâmica, após solicitação para que observassem o espaço da sala de aula, estabeleceu-se um tempo determinado, dando-se a seguir um sinal para que pudessem começar alguns diálogos e comentários - exposição participada e dialogada, acerca de algumas imagens ou objetos presentes no ambiente, quando cada acadêmico acrescentou algum comentário sobre o que observou em termos de formas visuais e as informações matemáticas e geométricas implícitas no ambiente e/ou no objeto analisado.

Os acadêmicos se empenharam nas atividades propostas, na formulação de alguns comentários e, posteriormente, volta-se a interferir nos diálogos para solicitar que olhem mais uma vez para o espaço da sala de aula, para que possam ampliar os comentários do grupo com relação à dinâmica das atividades em curso. Nesse momento, após mais algumas verificações dos licenciandos, expõem-se algumas atividades que articulam o Desenho Geométrico com a Matemática, considerando-se as observações feitas pelo grupo para favorecer a percepção de algumas possibilidades articuladoras entre os componentes em estudo.

No decorrer das atividades realizam-se comentários acerca de alguns conceitos matemáticos e geométricos, que se fizeram presentes nos exercícios de "olhar" e "ver" realizados no ambiente, com o propósito de esclarecer que tais aspectos que permeiam o trabalho serão utilizados, doravante, como parte das atividades e que deverão servir para descobrir referências geométricas e matemáticas no ambiente, no cotidiano, na vida em geral. Esclarecendo melhor a questão sobre percepção e análise do ambiente, Aumont (1993, p. 14) coloca o seguinte,

A visão, a percepção visual, é uma atividade complexa que não se pode, na verdade, separar das grandes funções psíquicas, a intelecção, a cognição, a memória, o desejo. Assim, a investigação, iniciada "do exterior", ao seguir a luz que penetra no olho, leva logicamente a considerar o sujeito que olha a imagem, aquele para quem ela é feita, o qual chamaremos de seu espectador.

Pelo exposto, depois de realizados alguns esclarecimentos e comentários, estimulamse os acadêmicos para que, a partir das informações, da dinâmica realizada e dos materiais de desenho geométrico disponíveis, solicitados anteriormente e, mediante a imaginação criadora, que elaborem atividades gráficas - desenhos, de acordo com as leituras visuais realizadas no ambiente da sala de aula, que estejam em sintonia com algumas representações de conceitos e elementos discutidos no encontro no que diz respeito ao conhecimento matemático associado ao Desenho Geométrico, enquanto campo de estudos. 


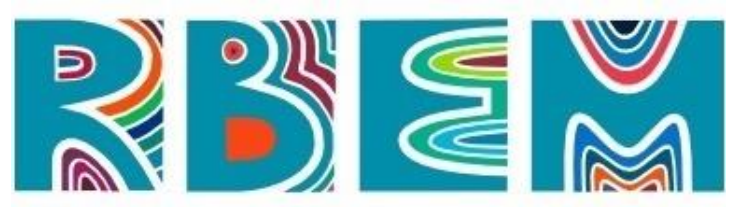

REVISTA BAIANA DE EDUCAÇÃO MATEMÁTICA

Dessa maneira, tentam-se ampliar as discussões e diálogos sobre o assunto, permitindo-se assim, estabelecer conexões para os encontros seguintes, sempre perguntando algo comentado nos encontros anteriores, para percebermos assimilações, lembranças, interrelações dos conteúdos, dentre outros aspectos, com o propósito de estabelecermos aprendizagens significativas devidamente articuladas com as propostas de cada encontro, uma vez que, consideram-se tais dados como qualitativos que poderão favorecer planejamentos e projetos vindouros, assim como, com as atividades propostas em cada encontro pedagógico.

Para melhor compreensão, a seleção dos participantes da pesquisa - primeira fase e fase final do curso ocorreram em face da necessidade de se estudar parte de um universo local, visto que a pesquisa tem por propósito generalizar os resultados individuais coletados, para considerar a população da qual os sujeitos pesquisados constituem uma amostra, sendo por isso que, a explicitação, seleção e eleição dos participantes com respectiva aplicação das atividades ocorreu com base em etapas e passos específicos estabelecidos no planejamento dos trabalhos para pesquisa.

Por tais motivos, optou-se pela pesquisa randômica com etapas respectivas (SOARES, 1991) que orientam uma distribuição aleatória intencional dos instrumentos para coleta de dados, contudo, com moderado controle em face dos objetivos do trabalho, sem comprometer a intencionalidade qualitativa e quantitativa dos dados, com o apoio de perguntas elaboradas previamente, para permitir a cada um dos acadêmicos possibilidades de participação da pesquisa, dos diálogos e da dinâmica.

Para tanto, adotou-se os seguintes passos e etapas para efetivação da pesquisa: definição do contexto ou ambiente de trabalho; planejamento das etapas e períodos; execução propriamente dita do trabalho investigativo; análise e interpretação dos dados obtidos e apresentação dos resultados por meio de quadro explicativo comparativo, com as respectivas interlocuções dos conteúdos ou assuntos enfocados.

Desse modo, os questionários aplicados junto aos acadêmicos da primeira fase ingressantes, foram discutidos e analisados posteriormente. Utilizou-se um período de 03 (três) semanas, nos horários habituais das aulas de Desenho Geométrico sem comprometer o andamento das atividades docentes, muito pelo contrário, enriquecendo-a durante cada encontro, com as perguntas, os comentários, os depoimentos, as experiências que os licenciandos recém-chegados portavam etc. 


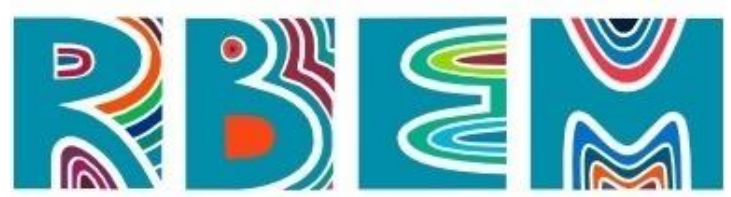

REVISTA BAIANA DE EDUCAÇÃO MATEMÁTICA

Cada questionário precisou em média de 30 minutos para ser respondido pelos acadêmicos da primeira fase - ingressantes. Isso aconteceu de forma muito livre e pessoal, sem consultas a internet, apenas com a utilização da memória e experiências estudantis dos novos acadêmicos e, contemplou questões tais como: que é Desenho Geométrico? Quando e aonde nasceu o Desenho Geométrico? As atividades realizadas por meio do Desenho Geométrico podem ser importantes? Comente. Quais os tipos de desenhos que você conhece? Você vê alguma relação entre a Matemática e o Desenho Geométrico? Comente. O que se pode aprender por meio do Desenho Geométrico? Que é Matemática? Você percebe algum objetivo com relação à oferta do componente curricular Desenho Geométrico para o curso a ser realizado? É possível ocorrer aprendizagens matemáticas por meio do Desenho Geométrico? Comentar. Entre outros.

O propósito foi realizar um debate com os acadêmicos na fase inicial do curso, com as respectivas vivências, para obtenção de um panorama sobre o assunto e, além disso, realizar pesquisa qualitativa, para percebermos se havia alguma percepção dos acadêmicos depoentes, os recém-chegados à Universidade, no que diz respeito às possíveis articulações entre a Matemática e o Desenho Geométrico, querendo com isso, perceber-se o entendimento dos envolvidos sobre o assunto.

No que tange a pesquisa com os acadêmicos mais para o final do curso - VIII, IX e X semestres, adotou-se para coleta dos dados um documento sob o formato de um quadro comparativo explicativo, que deveria ser preenchido conforme orientações estabelecidas. Foi preciso realizar-se uma exposição aberta dialogada e explicativa, nas salas de aula visitadas, no sentido de esclarecer os objetivos, as finalidades, os propósitos das ações na ocasião.

Participaram 24 (vinte e quatro) licenciandos dos 39 (trinta e nove) matriculados, incluindo-se alguns acadêmicos com prazo de conclusão de curso estendido. Essa coleta de dados requereu a utilização de quatro semanas para efetivação e obtenção das respostas, em decorrência de algumas situações que impediram momentaneamente a aplicação dos quadros explicativos comparativos, tais como: horários distintos, realização de atividades avaliativas, faltas de alguns participantes por questões profissionais ou pessoais etc.

Não foi possível reunir os acadêmicos num determinado horário ou local, em decorrência dos fatores citados, entre outros, para realização da atividade. Isso requereu por parte do pesquisador certas caminhadas pelas salas de aula do Campus, em dias alternados, 


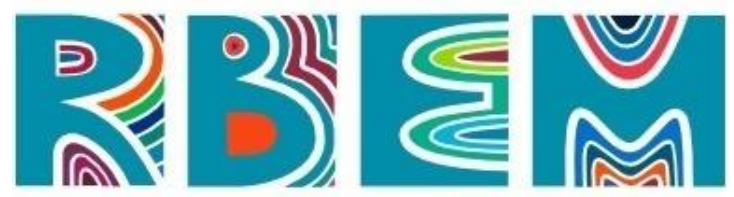

REVISTA BAIANA DE EDUCAÇÃO MATEMÁTICA

contando sempre com a compreensão dos docentes formadores para permitir o acesso às respectivas salas de aula. Vale lembrar, que (11) onze acadêmicos entre os participantes, preferiram preencher o documento no seu domicílio, por se sentirem mais a vontade, fomentar lembranças etc.

\section{Sobre desenho geométrico e matemática}

O Desenho Geométrico é um importante componente curricular. Por meio de traçados geométricos realizados com instrumentos tais como: régua, compasso, esquadros, escalímetros e transferidor poderá possibilitar o desenvolvimento do raciocínio lógico, da precisão, da organização matemática e geométrica, além da criatividade (MARMO e MARMO, 1994).

Além dos valores mencionados, o ensino do Desenho Geométrico pode ainda desenvolver a elaboração da autonomia, a sensibilidade para observar as formas geométricas na natureza e a sua aplicação na produção humana (JORGE, 1998).

Numa compreensão geral, o Desenho Geométrico é um suporte gráfico ligado a vavencin representações bidimensionais e tridimensionais, por servir para compreensão de projeções em planos, com o auxílio de pontos, linhas, formas planas e não planas e, envolve basicamente conceitos da Geometria, ramo da Matemática.

Para Silva (2006) e Costa (2013), a elaboração das construções geométricas pode contribuir para o entendimento e compreensão ampliada dos conceitos, das propriedades e das relações geométricas e algébricas, estudadas separadamente em Matemática. Nesse sentido, é correto afirmar que as relações entre a Matemática com o estudo das construções geométricas "são tão intrínsecas que, na maioria dos casos, é impossível entender as leis matemáticas sem os recursos gráficos presentes no Desenho Geométrico” (RAYMUNDO, 2010, p. 18).

Para estudar Desenho Geométrico na universidade, o licenciando precisa chegar com conhecimentos básicos sobre o assunto, sendo que a realização das atividades dessa natureza dependem de um conhecimento mínimo, mas que poderá facilitar o entendimento desse conhecimento específico. 


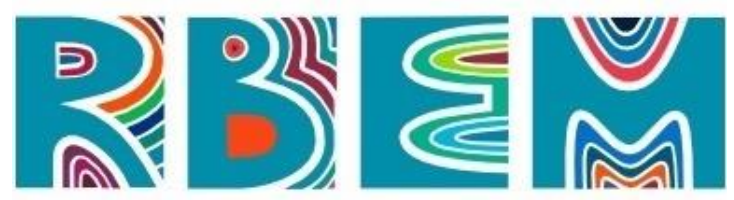

REVISTA BAIANA DE EDUCAÇÃO MATEMÁTICA

A respeito dessa questão, Zuin (2001) diz que o ensino das construções geométricas na disciplina Desenho Geométrico, propicia uma maior compreensão e embasamento teórico para o ensino da Geometria Plana, entre outras. Todavia, segundo o autor, apesar de sua importância e potencialidades, essa disciplina hoje é estudada em poucas escolas brasileiras, salvo algumas resumidas, quando oferecem cursos técnicos específicos (ZUIN, 2001).

No que concerne a Matemática, de modo geral, sabe-se que foi concebida mediante ações reflexivas, almejando-se um desempenho que possibilitasse aos estudantes proceder a análises, discussões, conjecturas, apropriação de conceitos, formulação de ideias, resoluções de problemas, observações práticas que necessitavam de estudos formais, ou seja, de amplitudes conceituais significativas, bem como, a percepção da vida numa perspectiva ampliada.

Por assim entender, a Matemática se torna uma ligação profícua entre campo de conhecimento e disciplina escolar (HELBEL, 2013), justamente por possuir este caráter articulador com outras áreas de conhecimento. Para Cifuentes (2005, p. 59) a compreensão é a seguinte:

A Matemática não deveria ser estudada priorizando-se apenas seus conteúdos, senão interpretada também em seus contextos históricos e culturais, e pondo em evidência não somente sua utilidade senão também a sua beleza, imbricada com outras áreas de conhecimentos ou campos de atuação.

Como se percebe, necessita-se de um projeto e ações com características integracionistas, que possa explicitar a articulação da Matemática com o Desenho Geométrico no que tange a aprendizagem, como criação, como reflexão e transformação do mundo subjetivo e objetivo, como resultado prático de uma produção conjunta entre a mão, o olho e a consciência individual e coletiva, ainda que, mediante uma forma particular e subjetiva de percepção de dados de aprendizagens.

Deve-se considerar também, os conteúdos específicos, próprios e estruturantes de ambas as componentes curriculares, para não descaracterizá-las, sempre as considerando conforme necessidades pedagógicas de quem articula e de quem aprende, sem desqualificar nenhum dos aspectos dos processos de ensino e de aprendizagem, visto que, são portadores de necessidades, objetivos, funções e peculiaridades. 


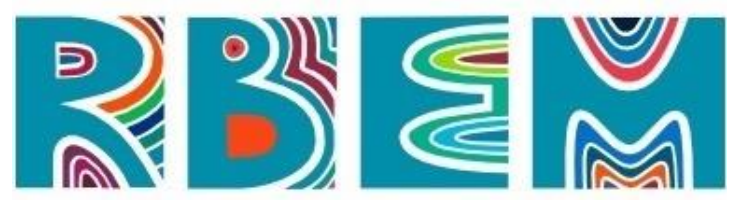

REVISTA BAIANA DE EDUCAÇÃO MATEMÁTICA

Dessa forma, pode-se perceber o quanto o Desenho Geométrico poderá influenciar no desenvolvimento da intuição e imaginação matemática, mediante vias ampliadas que objetivem o aprendizado de conteúdos matemáticos, entre outros, num viés articulador, dinâmico e plural.

As atividades proporcionadas pelo Desenho Geométrico poderão inclusive, facilitar a expansão do universo cultural dos estudantes, abrindo espaço para a participação social, onde aprender matemática por esse caminho poderá ser uma possibilidade profícua a ser vislumbrada em sala de aula, numa articulação muito significativa, de modo que, os estudantes possam se tornar partícipes de descobertas e protagonistas em um processo de investigação.

Assim, busca-se aproximar as elaborações dos licenciandos com padrões de realização não habituais, justamente para aguçar o olhar diferenciado e a criatividade com relação ao conhecimento matemático proporcionado pelo Desenho Geométrico, pois tal perspectiva poderá ser assegurada ao se trabalhar com informações, estratégias e metodologias que enfatizem, inicialmente, as realizações matemáticas do entorno que estão literalmente articuladas com o Desenho Geométrico.

Por meio das experiências vivenciadas, pode-se perceber o significado e a importância da aprendizagem matemática através do Desenho Geométrico num contexto participativo, dinâmico e vivo, por conseguinte, com criatividade no cotidiano dos licenciandos, o que nos permite perceber dados qualitativos para reflexões e previsões para encontros posteriores.

Cabe ressaltar que este é um tema de extrema relevância para o processo de ensino/aprendizagem matemática enquanto campo de conhecimento e/ou componente curricular, uma vez que, pode se constituir num importante fator de estímulo para trabalhos que priorizam atividades pedagógicas que articulem os componentes curriculares mencionados pelo trabalho, por intermédio de metodologias que sejam ativas e prazerosas, com possibilidades de diálogos interdisciplinares articuladores, como se pretende na atualidade.

\section{Discussões e evidencias de aprendizagens}




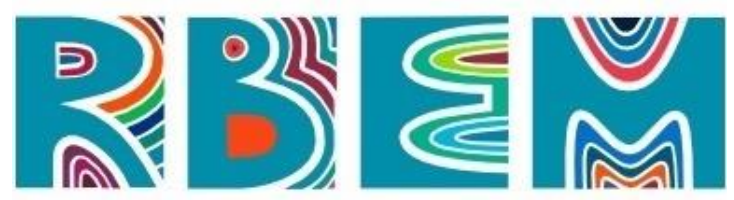

REVISTA BAIANA DE EDUCAÇÃO MATEMÁTICA

A pesquisa realizada com os acadêmicos da primeira fase - ingressantes do curso de licenciatura em Matemática enfatizou os dados coletados referentes aos questionários aplicados, com base nas questões iniciais que foram preparadas, aplicadas por intermédio de dinâmicas iniciais e apresentadas anteriormente.

Os resultados apontaram de forma geral, que eles entendem, sabem e conhecem algo sobre o histórico, algumas propriedades, as finalidades, algumas definições e conceitos, além de alguns objetivos do Desenho Geométrico quando articulado com a matemática, mesmo que de maneira solta e com inseguranças, conforme depoimentos obtidos na ocasião.

Vale salientar, que esses questionamentos, de cunho muito mais geral, foram respondidos pelos participantes de maneira satisfatória, sendo que, com a ajuda de uns e outros, conseguia-se obter alguma clareza nos depoimentos, aspecto muito importante para realização do trabalho, pois se conseguiu dialogar, inferir, integrar, valorizar, ouvir e formar uma compreensão coletiva entre os participantes sobre as questões colocadas durante a dinâmica, com a participação dos acadêmicos presentes.

No entanto, não foram esclarecedores nem enfáticos, quando se solicitou evidências com base em perguntas mais específicas e diretas, tais como: - O que se pode aprender por meio do Desenho Geométrico? Você percebe algum objetivo com relação à oferta do componente curricular Desenho Geométrico para o curso a ser realizado? É possível ocorrer aprendizagens matemáticas por meio do Desenho Geométrico? Constataram-se certas dificuldades para responder, com palavras e frase soltas, divagações, sem clareza e sem segurança nas poucas colocações feitas pelos participantes.

A pesquisa realizada com os acadêmicos mais ao final do curso apresentou situação bastante adversa em relação à percepção dos acadêmicos ingressantes, quando se solicitou aos matriculados dos semestres VIII, IX e X, do curso de Matemática, que preenchessem um quadro explicativo comparativo, que nos permitisse perceber, no decorrer dos componentes cursados e/ou em curso, em quais componentes ou em quais conteúdos, foi possível verificar articulações dos conteúdos e assuntos de Desenho Geométrico ofertado no primeiro semestre, com os assuntos e conteúdos dos componentes curriculares que cursaram a partir do segundo semestre até o momento da pesquisa.

Para realização dessa etapa da pesquisa, foram consultados 24 (vinte e quatro) licenciandos dos 39 (trinta e nove) distribuídos no VIII, IX e X semestres, inclusive com 


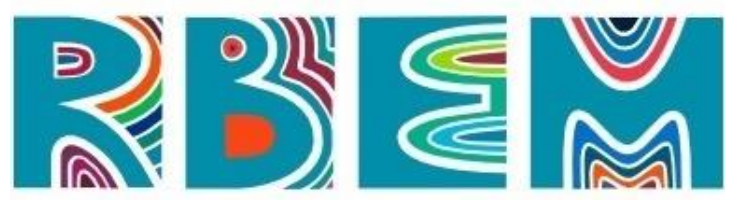

REVISTA BAIANA DE EDUCAÇÃO MATEMÁTICA

alguns que estavam com prazo de conclusão de curso estendido. Foi necessário o apoio documental de um quadro explicativo comparativo elaborado previamente, conforme se apresenta a seguir com as respostas dos acadêmicos, para obtenção das informações dos licenciandos que se encontravam numa fase mais para o final do curso. A distribuição dos quadros ocorreu de forma aleatória, contudo intencional (SOARES, 1991).

Diante das solicitações, foi possível coletar respostas, que estão dispostas no Quadro 1 a seguir, que sistematiza as principais informações que emergiram com a pesquisa de acordo com as colocações dos participantes que se encontravam mais ao final do curso.

Quadro 1 - Sobre a relação estabelecida entre os conteúdos de trabalho em Desenho Geométrico ofertados no primeiro semestre que são percebidos nos componentes curriculares ofertados ao longo do curso de Matemática

\begin{tabular}{|c|c|}
\hline $\begin{array}{c}\text { Conteúdos, assuntos ofertados no componente } \\
\text { curricular Desenho Geométrico. }\end{array}$ & $\begin{array}{c}\text { Conteúdos percebidos nos componentes curriculares } \\
\text { do curso de Matemática que tiveram o aporte do } \\
\text { Desenho Geométrico como embasamento para } \\
\text { aprendizagem matemática }\end{array}$ \\
\hline Ponto & Axiomas Geométricos (Geometria Plana) \\
\hline $\begin{array}{l}\text { Linhas e suas tipologias - retas, curvas, sinuosas, } \\
\text { segmento, semirretas, obliquas, perpendiculares, } \\
\text { paralelas etc. }\end{array}$ & $\begin{array}{l}\text { Axiomas geométricos e durante toda matéria de } \\
\text { Geometria Plana - retas, curvas, segmento, semirretas, } \\
\text { oblíquas, perpendiculares e paralelas. } \\
\text { Funções (Cálculos); } \\
\text { Geometria Espacial: prismas. }\end{array}$ \\
\hline Planos & $\begin{array}{l}\text { Geometria Plana: quando estudamos planos e suas } \\
\text { posições. Planos. }\end{array}$ \\
\hline Ângulo. Central, inscrito, retos etc. & $\begin{array}{l}\text { Matemática II: trigonometria; } \\
\text { Geometria Plana: triângulos, quadriláteros, ângulos de } \\
\text { duas retas paralelas cortadas por uma transversal. } \\
\text { Ângulos - central, inscrito, retas. }\end{array}$ \\
\hline $\begin{array}{l}\text { Circunferências e elementos... Raio, diâmetro, } \\
\text { flecha, tangentes, secantes, arcos, cordas, ângulos } \\
\text { no círculo etc. }\end{array}$ & $\begin{array}{l}\text { Cálculo I - tangentes, secantes... } \\
\text { Cálculo II - arcos. } \\
\text { Cálculo III: curvas de nível; } \\
\text { Geometria Plana: figuras planas. }\end{array}$ \\
\hline $\begin{array}{l}\text { Círculo e suas porções, superfícies ou áreas } \\
\text { circulares. }\end{array}$ & $\begin{array}{l}\text { Geometria Analítica II - círculo e suas porções, } \\
\text { superfícies e áreas circulares. } \\
\text { Cálculo II: integral; } \\
\text { Geometria Plana. }\end{array}$ \\
\hline Simetria e Assimetrias & $\begin{array}{l}\text { Geometria Plana; Laboratório do ensino de Matemática } \\
\text { III; } \\
\text { Geometria Espacial - simetria e assimetria. }\end{array}$ \\
\hline Polígonos regulares, irregulares, côncavos etc & $\begin{array}{l}\text { Geometria Plana - polígonos regulares, irregulares e } \\
\text { côncavos. }\end{array}$ \\
\hline Polígonos inscritos e circunscritos & $\begin{array}{l}\text { Geometria Plana e Espacial - polígonos inscritos e } \\
\text { circunscritos. Polígonos. }\end{array}$ \\
\hline
\end{tabular}




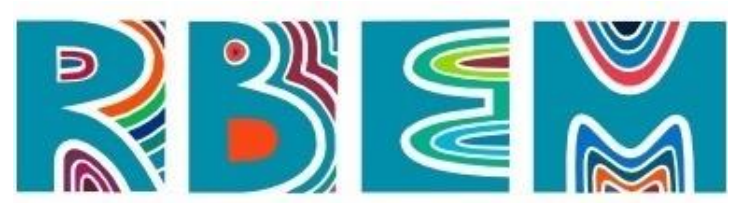

REVISTA baiana de EDUCAÇÃo MATEMática

\begin{tabular}{|c|c|}
\hline Semelhanças... Homotetias. & Geometria plana - semelhanças e homotetias. \\
\hline Escalas & Semelhanças. \\
\hline Segmentos proporcionais & $\begin{array}{l}\text { Geometria Plana. Estudos dos segmentos: proporcionais, } \\
\text { colineares, consecutivos, adjacentes. }\end{array}$ \\
\hline Concordâncias & $\begin{array}{l}\text { Geometria Plana - Estudo dos segmentos, perímetros, } \\
\text { concordâncias. }\end{array}$ \\
\hline Equivalência & $\begin{array}{l}\text { Geometria Plana; Lógica; Equivalência Lógica, } \\
\text { Proposições Equivalentes. Equivalência. }\end{array}$ \\
\hline $\begin{array}{l}\text { Curvas Cônicas - elipses, parábolas e } \\
\text { hipérboles. }\end{array}$ & $\begin{array}{l}\text { Geometria Analítica II; Cálculo de Integral Dupla e } \\
\text { Tripla; } \\
\text { Cálculo III e IV. } \\
\text { Geometria Espacial e Analítica } 2 \text { - Cônicas: elipses, } \\
\text { parábolas e hipérboles. }\end{array}$ \\
\hline Espirais e Falsas Espiras & $\begin{array}{l}\text { Geometria Plana - concordâncias, curvas consecutivas, } \\
\text { pontos colineares, polígonos, raios. }\end{array}$ \\
\hline $\begin{array}{l}\text { Curvas Cíclicas - cicloides, epiciclóides e } \\
\text { hipociclóides }\end{array}$ & $\begin{array}{l}\text { Geometria Analítica } 2 \text { - Curvas: cicloides, epicicloides e } \\
\text { hipocicloides. }\end{array}$ \\
\hline $\begin{array}{l}\text { Curvas diversas - estrofóides, conchóides, } \\
\text { cissóides, cúbicas, logarítmicas, catenária, curva } \\
\text { de Cassini, Quadratriz de Hippias, Lemniscata de } \\
\text { Bernoulli }\end{array}$ & $\begin{array}{l}\text { Matemática I: Funções. } \\
\text { Geometria Analítica II. }\end{array}$ \\
\hline
\end{tabular}

Fonte: Elaboração própria com base nos depoimentos dos participantes (2019)

As respostas apresentadas pelos participantes no Quadro 1, revelam a interferência do Desenho Geométrico em inúmeros momentos do curso de Licenciatura em Matemática, havendo naturalmente, mais preponderância nos componentes - Geometria Plana, Geometria Espacial e Cálculos, conforme registrado pelos depoentes.

Contudo, percebe-se farta utilização dos assuntos em outros componentes ao longo da realização da licenciatura em diversos semestres, fato que, expressa a importância e responsabilidade da mediação pedagógica em Desenho Geométrico, de modo que, possa de fato, ser assimilado à bem dos acadêmicos envolvidos no processo.

Tais repercussões verificadas requerem a utilização de técnicas e meios variados para geração de conhecimentos, inclusive tecnológicos - softwares, meios digitais variados, sem desconsiderar os utensílios manuais - esquadros, compassos, transferidores, réguas etc., para constituir, seguramente, formas de atrair a atenção e garantir o sucesso constante da 


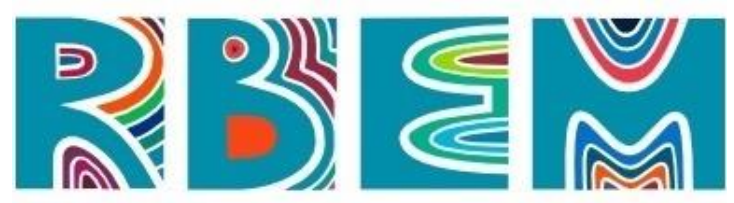

REVISTA BAIANA DE EDUCAÇÃO MATEMÁTICA

aprendizagem para os estudantes de Matemática por intermédio inclusive do aporte do Desenho Geométrico.

Essas constatações são importantes, tendo em vista que o trabalho pedagógico, ou seja, a mediação pedagógica deve contemplar, entre outras dimensões, a perspectiva da aprendizagem, diretamente influenciada pela perspectiva de ensino ou mediação. Além disso, é necessária a compreensão de que todo o trabalho demandado em Desenho Geométrico visa, antes de outros aspectos, a aprendizagem dos acadêmicos, nunca de maneira solta, aleatória, mecânica, dissociada do contexto matemático e geométrico, propriamente dito.

Por isso, pode-se perceber que o Desenho Geométrico é uma linguagem gráfica que exerce um elo entre a geometria e a álgebra contribuindo com o aprendizado dos licenciandos em relação às propriedades e demonstrações desses saberes (COSTA, 2013). Nesse sentido, existe uma relação perfeita entre o Desenho Geométrico e a geometria, pois ambas estudam as figuras geométricas com seus conceitos e suas propriedades, tendo naturalmente, especificidades no trato de um e de outro componente curricular, no que tange a esse tipo de aprendizagem.

O Desenho Geométrico é a geometria gráfica (MARMO e MARMO, 1994, p. 12). Nessa perspectiva, a Geometria e o Desenho Geométrico "são conceitos que estão relacionados diretamente à Matemática numa relação de interdependência, por isso, é inquestionável a importância de uma abordagem articulada desses conhecimentos" (QUEIROZ, 2010, p. 9-10).

Pelo exposto, considera-se que os métodos de ensino e de aprendizagem e o uso das metodologias participativas nos diversos momentos da mediação pedagógica de Desenho Geométrico, poderão ser relevantes para a formação acadêmica dos graduandos em Matemática, que poderão atuar, posteriormente, na escola básica, nos cursos técnicos, universidades, faculdades etc., como docentes que articulam e vislumbram possibilidades pedagógicas muito ricas, ao contribuírem para o processo de ensino e de aprendizagem de conceitos matemáticos por estimularem o desenvolvimento da criatividade, da organização, além de estimular a utilização de estratégias inovadoras para a resolução de problemas, por intermédio da componente curricular Desenho Geométrico.

Desse modo, é conveniente registrar que o objetivo inicial pensado para o trabalho de pesquisa, no que diz respeito à percepção dos acadêmicos numa fase inicial e numa fase 


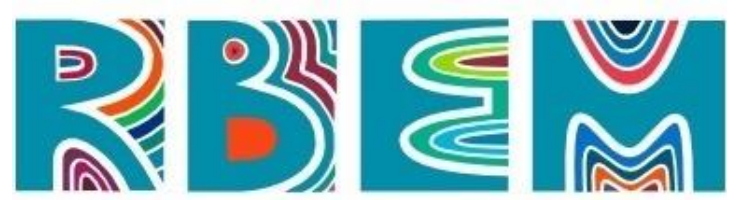

REVISTA BAIANA DE EDUCAÇÃO MATEMÁTICA

posterior mais ao final do curso de licenciatura em Matemática, quanto à interferência dos conteúdos e assuntos de Desenho Geométrico como aporte para a aprendizagem matemática, foi obtido, uma vez que, permitiu ao pesquisador enxergar com mais nitidez necessidades para o desempenho docente diante da formação dos acadêmicos, que possam facilitar os processos de ensino e de aprendizagem.

\section{Algumas considerações transitórias}

Dentre as proposições futuras estimuladas pela pesquisa, pode-se perceber que, os programas de cursos presenciais para professores, atividades extensionistas, voltados para a melhor utilização dos recursos didáticos disponíveis, que sejam também concebidos tendo como base os princípios de uma proposta articuladora e interacionista, devem ser considerados numa formação permanente dos acadêmicos em matemática, para que propiciem de fato o estudo e a reflexão constante acerca daquilo que se propõem a fazer de melhor em sala de aula.

Tais proposições poderão ocorrer também, para que os professores de matemática num processo formativo permanente, possam incorporar mais habilidades necessárias para o seu exercício profissional e, consequentemente, encontrar sentido para o que se "ensina" e se "aprende" devidamente associado com a vida em geral.

Desse modo, a percepção atual que se tem sobre a Matemática e o Desenho Geométrico, não devem contemplar nem um ensino dirigido e baseado em modelos prontos, nem a liberdade completa, sem nenhuma ação do mediador. Deve-se trabalhar com uma visão de linguagem, de articulação e comunicação, formada por elementos próprios e específicos, que estruturem uma forma de expressão ampla, refinada, necessária e rica, desde que bem ministrada, sempre a bem do conhecimento matemático bem compreendido por todos os envolvidos.

Teve-se também, a oportunidade, no andamento dos encontros semestrais na universidade com os acadêmicos, de dialogar com autores que elegeram o Desenho Geométrico como objeto de trabalho, o que nos fez enriquecer significativamente as noções que se tinha inicialmente sobre o assunto. 


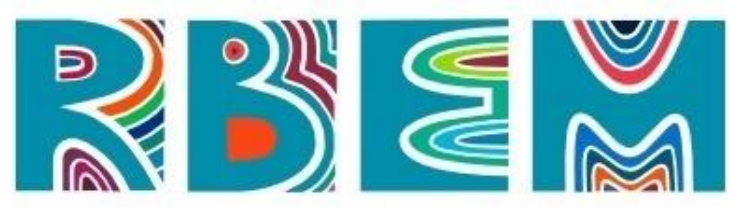

REVISTA BAIANA DE EDUCAÇÃO MATEMÁTICA

Foram percorridos os objetivos iniciais da pesquisa com os acadêmicos da primeira fase - os licenciandos de matemática do primeiro semestre letivo, para coleta das percepções que traziam e, posteriormente, coletou-se a percepção dos licenciandos dos semestres mais avançados, mais ao final do curso, até o último semestre em processo de conclusão, para obtenção de um quadro comparativo explicativo.

A pesquisa possibilitou aos envolvidos a capacidade de responder as questões apresentadas, mediante vivências próprias, sob a forma de uma ação transformadora, objetivando facilitar a busca de soluções para aspectos importantes vinculados à formação acadêmica e a práxis docente, objetivando compreender a realidade e nela penetrar, dialogar e promover reflexões, para constituir um rico espaço de formação, com sujeitos envolvidos no contínuo da pesquisa, numa coalizão de esforços dos participantes.

Assim, o processo de conhecimento dos acadêmicos esteve diretamente relacionado com a ampliação e reformulação do conhecimento do docente formador. Aprendemos muito e temos muito a aprender. Percebemos que não basta possuir um curso superior é preciso formação específica, com capacitações regulares ao longo da vida profissional para que as mediações pedagógicas ocorram de maneira eficaz.

\section{Referências}

AUMONT, Jacques. A imagem. Campinas - SP: Papirus, 1993.

CIFUENTES, José C. Uma via estética de acesso ao conhecimento matemático. Boletim GEPEM, Rio de Janeiro, n.46, p.55-72, 2005.

COSTA, E. A. S; Analisando algumas potencialidades pedagógicas da história da matemática no ensino e aprendizagem da disciplina desenho geométrico por meio da teoria fundamentada. (242 fls); Dissertação de Mestrado Profissional em Educação Matemática. Departamento de Matemática. Ouro Preto, MG: Universidade Federal de Ouro Preto, 2013.

D’AMBRÓSIO, Ubiratan. Educação Matemática: da teoria à prática. 13. ed. Campinas, SP: Papirus, 2006.

GIL, António Carlos. Como elaborar projetos de pesquisa. 4.ed. São Paulo: Atlas, 2008. 


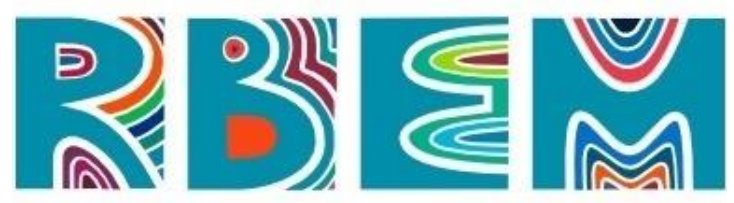

REVISTA BAIANA DE EDUCAÇÃO MATEMÁTICA

HELBEL. Ana Paula Tomazini. Matemática e Arte: possibilidades para o processo de ensino e aprendizagem da Geometria. Os desafios da escola pública paranaense na perspectiva do professor - Produções didático-pedagógicas - Cadernos PDE, 2013.

JORGE, Sonia. Desenho Geométrico: Ideias e imagens. São Paulo, SP: Saraiva, 1998.

MARMO, C.; MARMO, N. Desenho Geométrico. Rio de Janeiro, RJ: Scipione, 1994.

QUEIROZ, J. C. S., A Geometria e o Desenho Geométrico nas escolas do Brasil do século $X X$. X Encontro Nacional de Educação Matemática Educação. Matemática, Cultura e Diversidade, Salvador - BA, 2010.

RAYMUNDO, M. F. S. M. Construção de conceitos geométricos: investigando a importância do ensino do desenho geométrico nos anos finais do ensino fundamental; (120 fls); Dissertação de Mestrado em Educação Matemática. Vassouras, RJ: Universidade Severino Sombra, 2010.

SILVA, C. I. D. N. Proposta de aprendizagem sobre a importância do desenho geométrico e da geometria descritiva; (102 fls); Dissertação de Mestrado. Curitiba, PR: Pontifícia Universidade Católica do Paraná, 2006.

SOARES, J. F., FARIAS, A. A., CESAR, C.C. Introdução à Estatística. Rio de Janeiro, Ed. Guanabara Koogan S.A., 1991, p. 235.

ZUIN, E. S. L. Da régua e do compasso: as construções geométricas como um saber escolar no Brasil. (211 fls); Dissertação (Mestrado em Educação) - Faculdade de Educação, Universidade Federal de Minas Gerais, Belo Horizonte, 2001.

Artigo submetido em: 18/07/2020

Artigo aceito em: 29/08/2020 